\title{
Determination of anomalous pulmonary venous return with high-pitch low-dose computed tomography in paediatric patients
}

\author{
E. Gözgeç ${ }^{1}$, M. Kantarci ${ }^{1}$, F. Guven${ }^{1}$, H. Ogul' ${ }^{1}$ N. Ceviz² ${ }^{2}$ S. Eren ${ }^{1}$ \\ ${ }^{1}$ Department of Radiology, School of Medicine, Ataturk University, Erzurum, Turkey \\ ${ }^{2}$ Department of Paediatric Cardiology, School of Medicine, Ataturk University, Erzurum, Turkey
}

[Received: 12 January 2020; Accepted: 14 March 2020]

Background: In this study, we aimed to image pulmonary venous return anomalies and associated cardiovascular and pulmonary abnormalities by high-pitch low-dose computed tomography (CT) in children.

Materials and methods: Forty-one patients with total or partial anomalous pulmonary venous return anomalous between May 2012 and June 2019 were retrospectively reviewed. The anomalies were determined using high-pitch low-dose CT. The patients' mean age was 3 years (6 months to 15 years), and 24 of them were female.

Results: There were 10 patients with total pulmonary venous return anomalies (TPVRA) and 31 patients with partial pulmonary venous return anomalies (PPVRA). Six (60\%) patients with TPVRA had the supracardiac type, 2 (20\%) had the cardiac type, and 2 (20\%) had the mixed type. All patients with TPVRA had a large atrial septal defect (ASD), 1 patient also had patent ductus arteriosus, and 1 patient had right cardiac hypertrophy. Forty cases of PPVRA were found in 31 patients. Twenty-seven (67\%) of them were right-sided, and 13 were left-sided (33\%). Twenty (65\%) patients also had an additional cardiovascular anomaly (ASD in 12 patients, persistent superior vena cava in 4 patients, patent ductus arteriosus in 3 patients, and aortic coarctation in 2 patients). Of the 27 patients with right-sided PPVRA, it drained into the superior vena cava in 19 patients, the right atrium in 5 patients, and the inferior vena cava in 3 patients. In left-sided cases, the anomalous pulmonary vein drained into the left innominate vein in 9 patients, and in 4 patients, there were accessory pulmonary veins that drained into the left innominate vein. Many of the patients had additional lung anomalies, including pneumonic infiltration $(n=12)$, atelectasis $(n=8)$, and lobar emphysema $(n=5)$, and some of these findings coexisted.

Conclusions: Anomalous pulmonary venous drains and associated cardiac and extra-cardiac anomalies can be detected reliably and quickly with high-pitch low-dose CT without sedation in paediatric patients. (Folia Morphol 2021; 80, 2: 336-343)

Key words: anomalous pulmonary venous return, high-pitch, low-dose computed tomography, paediatric patients 


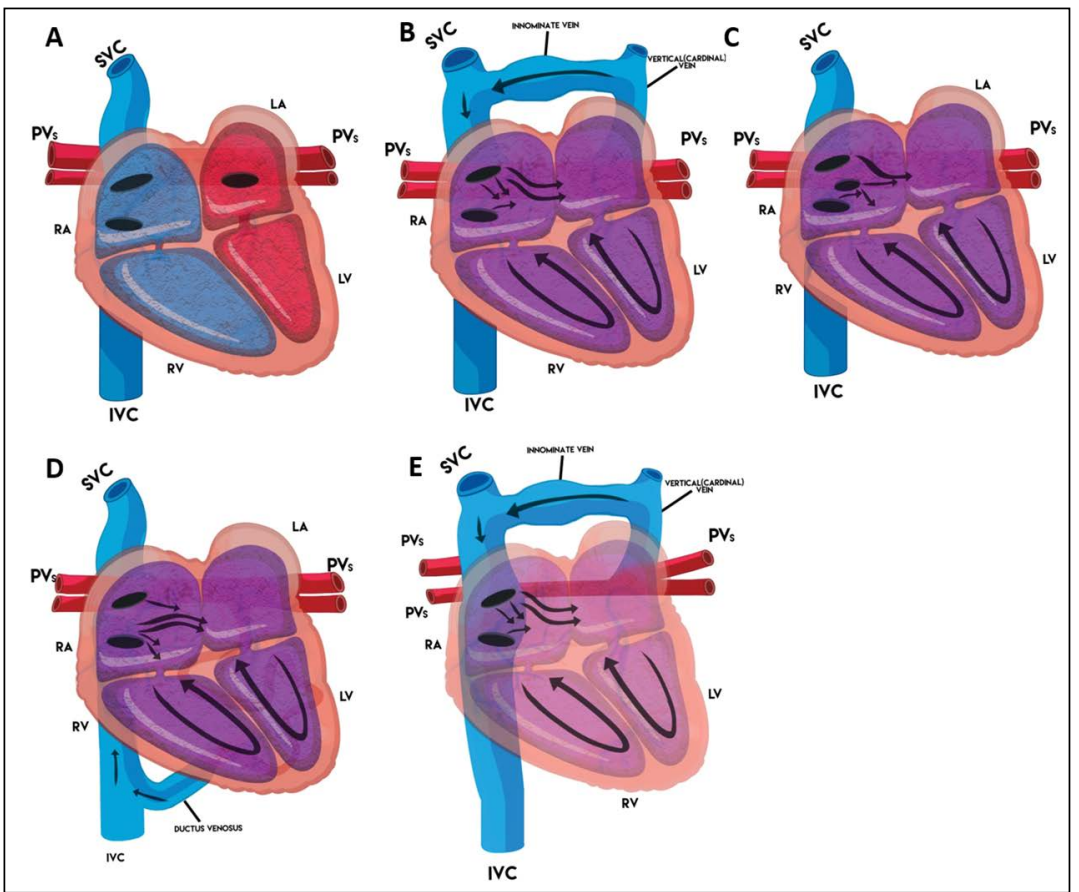

Figure 1. A-E. The types of total pulmonary venous return anomaly. Normal $(\mathbf{A})$, supracardiac type (B), cardiac type (C), infracardiac type (D) and mixed type (E); SVC — superior vena cava; PVs pulmonary veins; $\mathrm{RA}$ — right atrium; $\mathrm{LA}$ left atrium; RV — right ventricle; LV left ventricle; IVC — inferior vena cava.

\section{INTRODUCTION}

Pulmonary venous return anomalies (PVRA) result from one or more pulmonary veins draining into the systemic circulation instead of the left atrium. PVRA constitutes $1.5-5 \%$ of all congenital heart diseases and is divided into two main groups: total and partial. In total pulmonary venous return anomalies (TPVRA), all of the pulmonary veins drain into the systemic circulation rather than the left atrium. This condition causes left-to-right shunt and often cyanosis. Although it is usually isolated, it may also be a part of complex heart diseases, such as heterotaxis $[8,15,17]$.

Total pulmonary venous return anomalies are divided into four groups depending on where it is drained: supracardiac, cardiac, infracardiac, and mixed. The supracardiac form is the most common type of TPVRA (45-49\%). In this type, all pulmonary veins merge in a confluence and then drain through the vertical vein to the innominate vein, superior vena cava (SVC), or other veins above the heart. The vertical vein is often seen in front of the left pulmonary vein, but if it passes behind, it causes obstruction. In the cardiac type, commonly, the confluence is connected to the right atrium via the coronary sinus. In the infracardiac type, which is a less common form of TPVRA $(11 \%)$, the confluence drains into any vein below the diaphragm, the most common being the portal vein. This form is frequently associated with obstruction
(> 90\%), so patients have respiratory distress and a high mortality rate. The mixed type TPVRA comprises different combinations of the other three anomalies (Fig. 1A-E) $[8,18,21]$.

Partial pulmonary venous return anomalies (PPVRA) involve the connection of one or more pulmonary veins (but not all) to systemic veins. The prevalence of PPVRA is $0.4-0.7 \%$ in children and it is usually asymptomatic $[5,10]$. Patients with PPVRA usually have the sinus venosus type of atrial septal defect (ASD) (42\%), and up to $80-90 \%$ of patients with this ASD have PPVRA [3, 11]. PPVRA most commonly occurs on the right side, and the anomalous vein drains to the SVC in children [1]. Left-side PPVRA are seen more in adult patients, and they occasionally drain into the left brachiocephalic vein. Schimitiar syndrome is a less common type of PPVRA and occurs when the right inferior or right common pulmonary vein continues with the inferior vena cava [16]. The determination of venous return anomalies and especially concomitant cardiovascular and pulmonary anomalies is important to determine the course of patients.

Traditionally, echocardiography is the most commonly used diagnostic method, and catheter angiography is the gold standard. Cardiac magnetic resonance imaging also provides good structural and functional information. However, all these imaging modalities have various advantages, disadvantages, 
and different limitations in paediatric patients $[4,17$, 19]. In recent years, multidetector computed tomography (CT) has been used more frequently in congenital heart disease to evaluate cardiac and extra-cardiac structures, but radiation is a known disadvantage. To overcome this drawback, a number of filtering and low-dose techniques have been developed. One of these is the high-pitch and lowdose technique, which gives important information in a short time without utilising sedation. These features provide an important advantage, especially in very sick or uncooperative children $[6,7,9,12,14]$.

In this study, we aimed to investigate the value of high-pitch low-dose CT in demonstrating cardiac anomalies, as well as associated vascular and pulmonary pathologies in children with PVRA. To the best of our knowledge, this is one of the largest studies to show both TPVRA and PPVRA by high-pitch low-dose CT.

\section{MATERIALS AND METHODS}

In this study, we retrospectively examined the records of patients who were diagnosed with PVRA using CT angiography at our institution between May 2012 and June 2019. The mean age of the 41 patients was 3 years ( 6 months to 15 years old), and 24 of them were female. Catheter angiography was also performed in some patients (14 patients). Ethics committee approval was obtained in accordance with the ethical considerations set out in the Declaration of Helsinki.

Patients underwent high-pitch low-dose CT for extra-cardiac, lung, or other pathologies with a three-dimensional configuration in preoperative preparation. All CT angiography examinations were performed using a dual-source CT system (Definition Flash, Siemens Healthcare). All scans were performed with free breathing. The imaging parameters included a gantry time of $280 \mathrm{~ms}$ and sectional collimation of $128 \times 0.6 \mathrm{~mm}$ by the $z$-flying focal spot technique. The table speed was $411 \mathrm{~mm} / \mathrm{s}$, and the high pitch was 3.4 for the examinations. The tube current and voltage were adapted to the patient's weight. The scan field was started under the neck and extended below the diaphragm.

The contrast agent (iopromide, $350 \mathrm{mg} \mathrm{I/mL} \mathrm{Ul-}$ travist, Bayer HealthCare) was administered at a rate of $1 \mathrm{~mL} / \mathrm{sn}$ via the peripheral vein at a dose of $1.5 \mathrm{~mL}$ $/ \mathrm{kg}$. A chaser saline solution was injected at $1.0 \mathrm{~mL} / \mathrm{kg}$ body weight after the contrast material. Vacuum-lock cushions were utilized to immobilise the patient. After the contrast and chaser saline solution were injected, the scan was started when the left ventricular cavity was clearly visualised. None of the patients required sedation or beta-blocker therapy.

Image reconstructions were conducted with a slice thickness of $0.75 \mathrm{~mm}$. All shots were completed without any complications. Images were processed on a Workstation (Syngo Via, Siemens HealthCare). Retrospectively, two radiologists and a paediatric cardiologist who had more than 10 years of experience reviewed all of the images, and decisions were made together. Pulmonary venous return anomalies were compared with catheter angiography results.

\section{RESULTS}

Pulmonary venous return anomalies were determined in 41 patients. TPVRA occurred in 10 patients, $6(60 \%)$ patients had the supracardiac type, $2(20 \%)$ of them had the cardiac type, and $2(20 \%)$ of them had the mixed type. In the supracardiac cases, the right and left pulmonary veins were connected posterior to the left ventricle, and this confluence was drained to the left innominate vein via a vertical vein in all patients (Fig. 2). One of these 6 patients also had right ventricular hypertrophy.

In the cardiac TPVRA cases, all of pulmonary veins were connected to the right atrium directly by a confluence (Fig. 3). Large ASDs were found in all patients with the cardiac and supracardiac forms of TPVRA, and the SVC was dilated in supracardiac cases. In mixed-type patients, the right upper vein was drained to the SVC, and the other veins were drained to the left innominate vein through a vertical vein (Fig. 4). One of patients with mixed-type TPVRA had patent ductus arteriosus (PDA), and one of them also had ASD.

Forty cases of PPVRA were imaged in 31 patients, and 27 of them were right-sided $(67 \%)$, while 13 were left-sided (33\%). Twenty-one patients had one anomalous pulmonary vein, and 10 patients had two. Of the 27 patients right-sided PPVRA, it drained into the SVC in in 19 patients (Fig. 5), the right atrium in 5 patients, and the inferior vena cava in 3 patients (Fig. 6). Among the 13 left-sided cases, the anomalous pulmonary vein drained into the left innominate vein in 9 patients (Fig. 7), and there were accessory pulmonary veins draining into the left innominate vein in 4 patients (Fig. 8). The anomalies found in $\mathrm{CT}$ correlated with the catheter angiography results. 

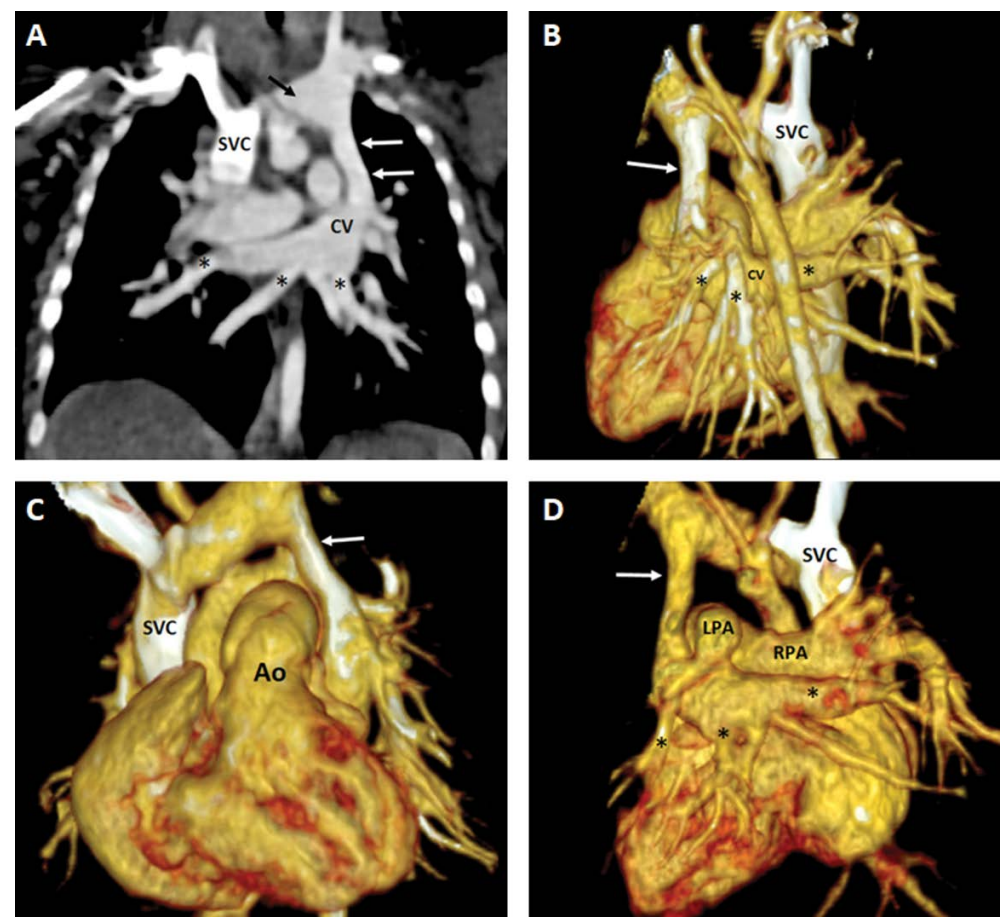

Figure 2. A-D. A 6-month-old male patient with supracardiac type total pulmonary venous return anomaly. Coronal maximum intensity projections computed tomography image (A) shows confluence of pulmonary veins (CV), vertical vein (white arrows) and left innominate vein (black arrow). Lateral-posterior (B), anterolateral (C) and posterior (D) three-dimensional volume-rendered computed tomography image demonstrates vertical vein (white arrow) and confluence vein (CV); SVC - superior vena cava; asterisks - pulmonary veins; $A 0$ - aorta; LPA — left pulmonary artery; RPA — right pulmonary artery.
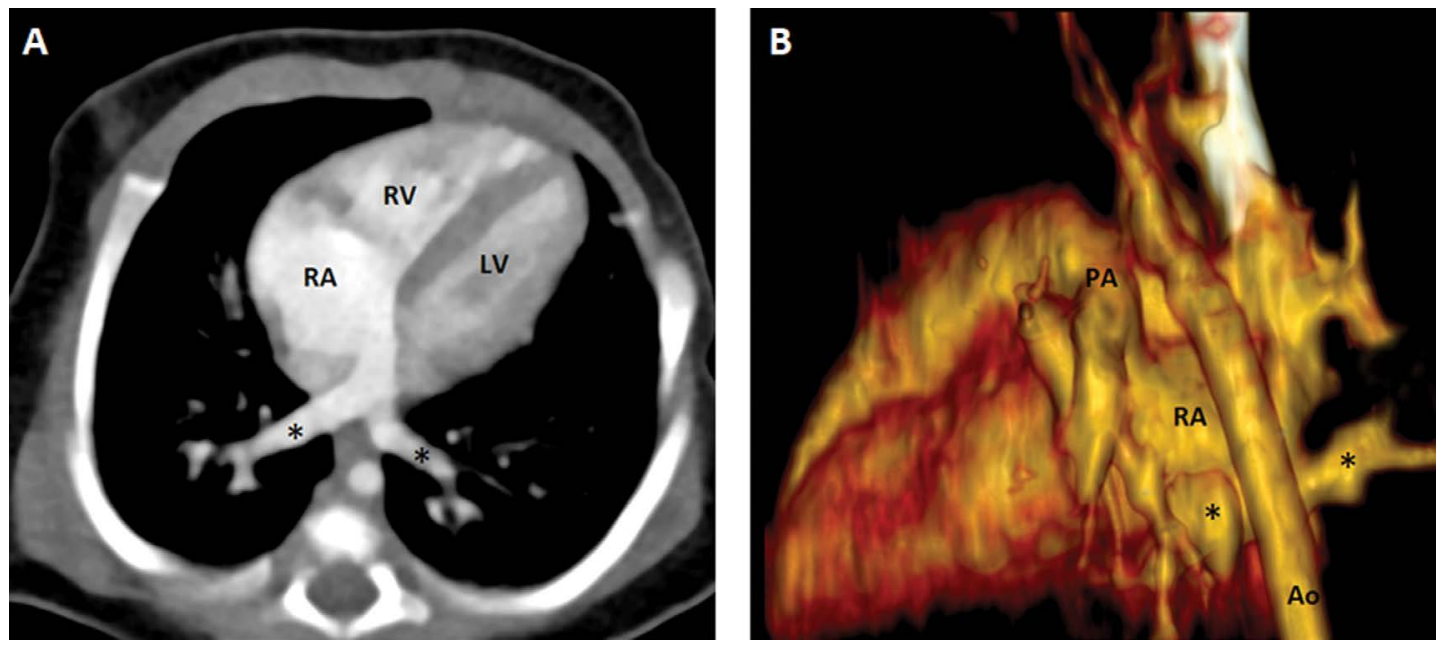

Figure 3. A, B. A 7-month-old male patient with cardiac type total pulmonary venous return anomaly. Axial computed tomography image (A) demonstrates right and left pulmonary veins drain into the right atrium. Posterior-lateral three-dimensional volume-rendered computed tomography image (B) shows anomalous of pulmonary drainage; asterisks — pulmonary veins; PA — pulmonary artery; RA — right atrium; $\mathrm{RV}$ - right ventricle; LV — left ventricle; Ao — aorta.

Eleven patients had only PPVRA, while the other ones had additional cardiovascular anomalies. There was ASD in 12 patients, persistent SVC (PSVC) in 4 patients, PDA in 3 patients, and aortic coarctation in 2 patients. Only 2 patients who were left-sided had additional cardiovascular anomalies.

Most of the patients with PVRA had different pulmonary findings. Additional lung anomalies included pneumonic infiltration $(n=12)$, atelectasis $(n=8)$, and lobar emphysema $(n=5)$, and some of these findings coexisted. Lung findings were detected in 4 of the patients with TPVRA and 11 of the patients with PPVRA (Table 1). The effective radiation dose was determined as $1.01 \mathrm{mSv}$ (range: $0.12-4.06 \mathrm{mSv}$ ), but $0.55 \mathrm{mSv}$ (range: $0.15-0.68 \mathrm{mSv}$ ) was used for patients under 1 year old.

\section{DISCUSSION}

The detection of PVRA and associated cardiovascular and lung anomalies is very important in deter- 

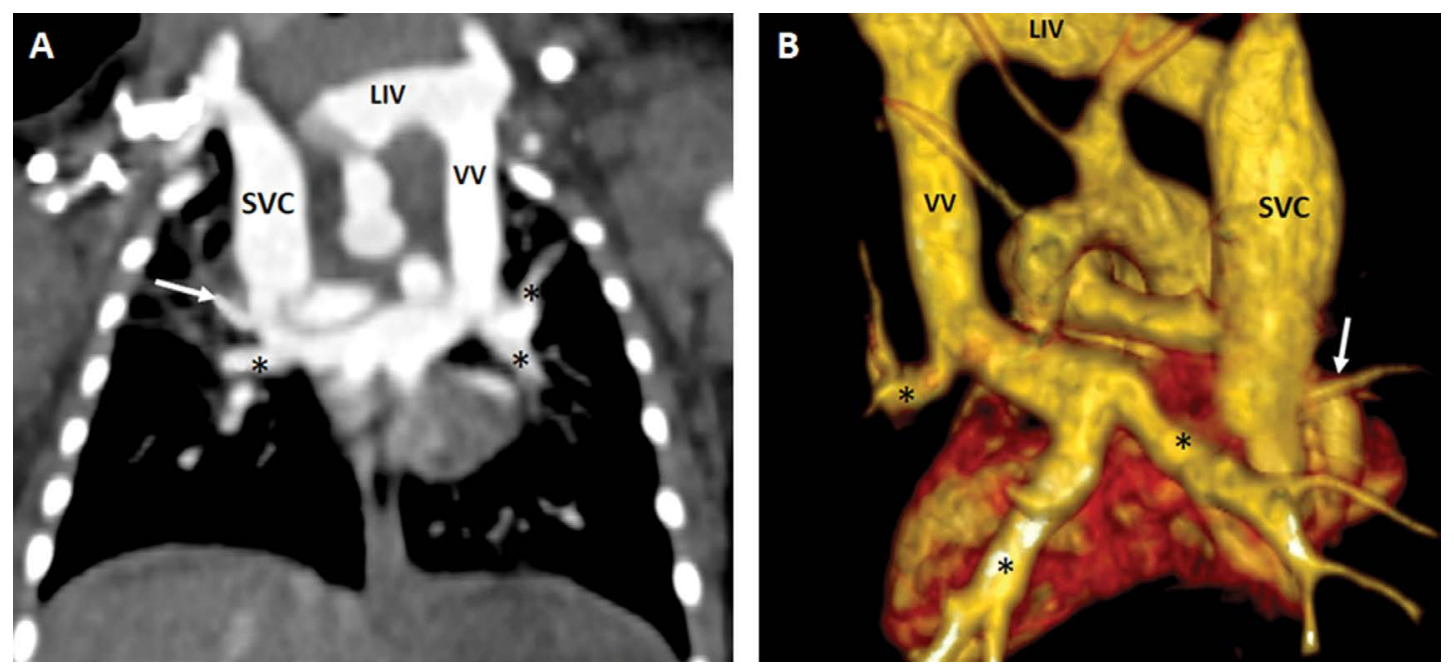

Figure 4. A, B. A female patient with mixed type total pulmonary venous return anomaly. Coronal maximum intensity projections computed tomography image (A) and posterior three-dimensional volume rendered images (B) demonstrates right upper pulmonary vein (white arrow) directly drain to superior vena cava (SVC) and other pulmonary veins (asterisks) drained to left innominate vein (LIV) via a vertical vein (VV).
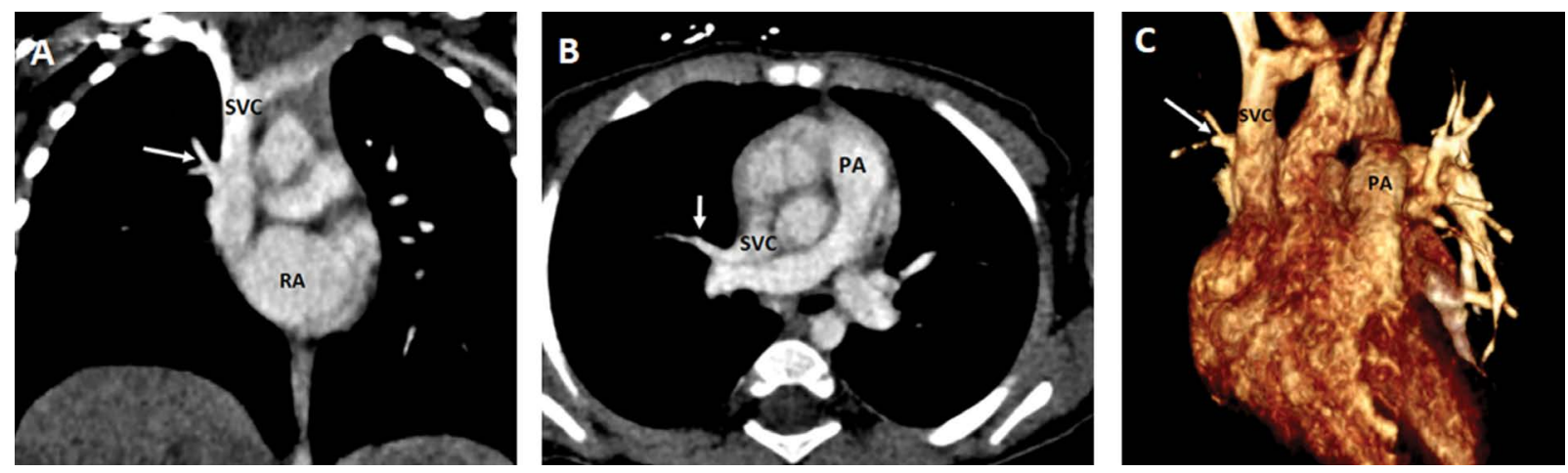

Figure 5. A-C. Right upper pulmonary vein directly drains into superior vena cava in 8-year-old male patient with partial pulmonary venous return anomaly. Coronal (A), axial (B) and anterior three-dimensional volume rendered images show anomalous pulmonary vein (white arrow; SVC — superior vena cava; RA — right atrium; PA — pulmonary artery.
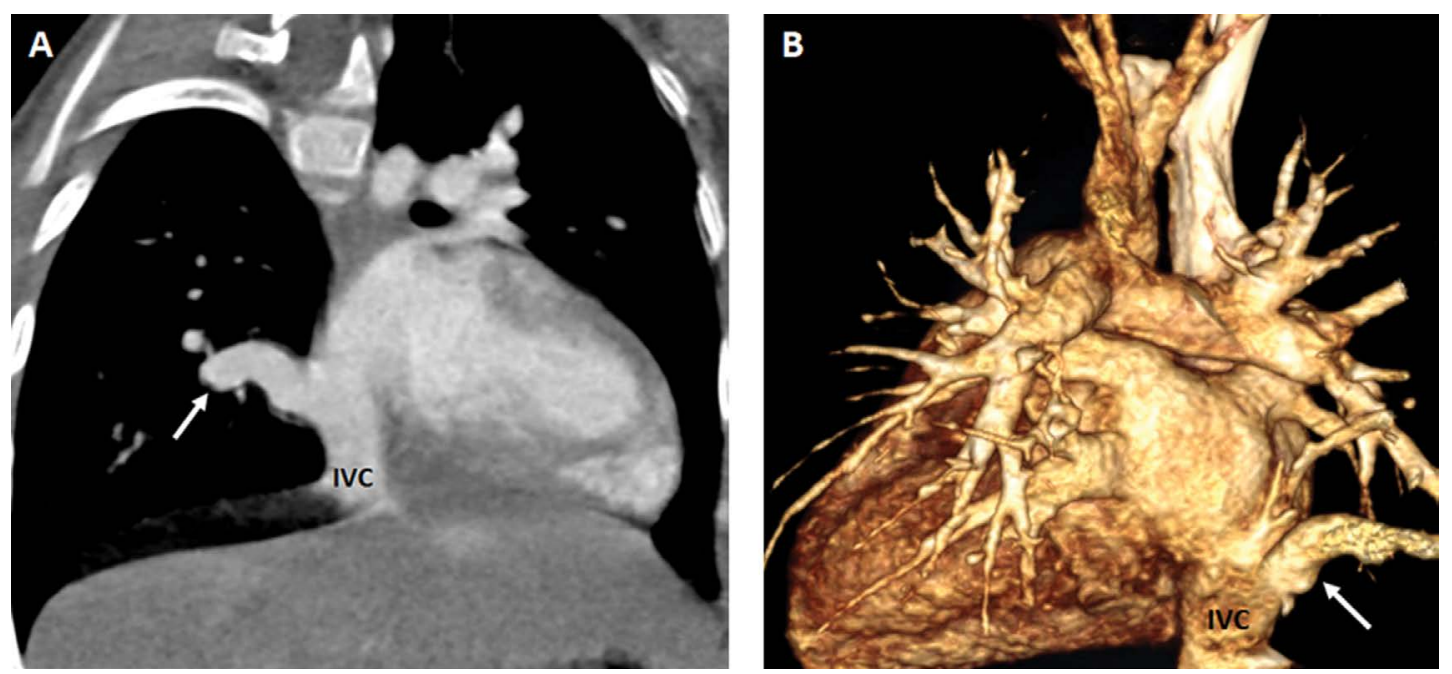

Figure 6. A, B. A 9-year-old female patient with partial pulmonary venous return anomaly. Curved coronal and posterior-lateral three-dimensional volume rendered computed tomography images show anomalous right lower pulmonary vein (white arrow) drains into inferior vena cava (IVC). 


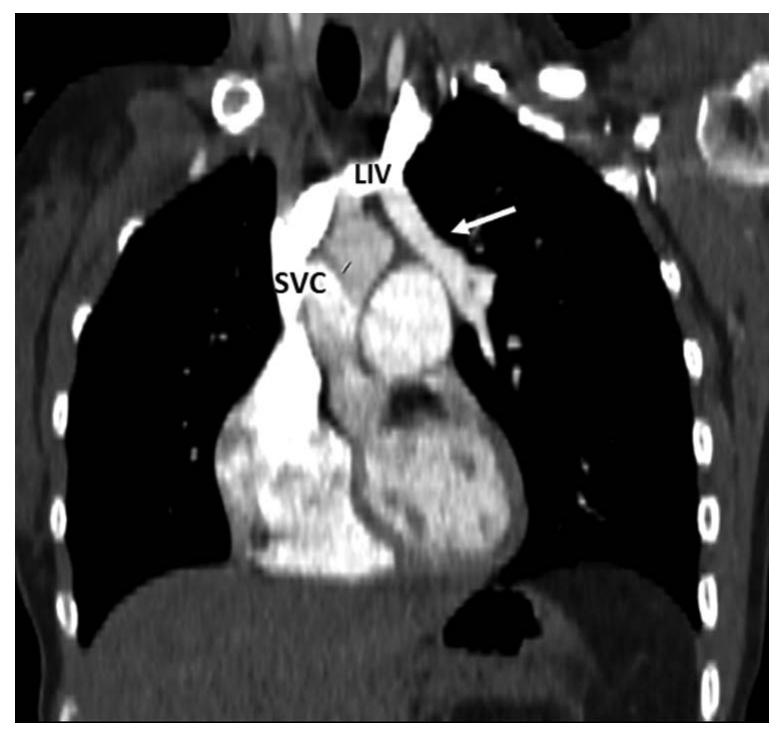

Figure 7. Partial pulmonary venous return anomaly at left upper pulmonary vein in a 7-year-old female patient. Coronal computed tomography image shows anomalous pulmonary vein (white arrow); LIV — left innominate vein; SVC — superior vena cava.

mining treatment plans for children. PPVRA should be examined because it changes the surgical treatment plan, especially in patients with ASD. Although plain $X$-ray images are notoriously typical in patients with TPVRA, further imaging is required to detect additional anomalies and confirm the diagnosis. Echocardiography is the first and most commonly used method to detect PVRA, but this method is inadequate due to the fact that the veins draining into the SVC are distant from the chest wall, as well as the method being user dependent and having a poor acoustic window.

The use of catheter angiography, which is the gold standard in the diagnosis, is limited because it requires sedation and high radiation in paediatric patients. In addition, complications are important limitations as the procedure is invasive. Magnetic resonance imaging is highly advantageous in that it is non-invasive and is free of ionising radiation. It also provides accurate information about cardiac and extra-cardiac structures and provides flow measurement. But the long duration of the shots and the necessity of sedation and breath holding create significant limitations.

Children are more susceptible to radiation than adults. Since radiation exposure is the most important problem in CT imaging, attempts have been made to minimise it with high-pitch low-dose screening. In recent years, the use of high-pitch low-dose CT has increased considerably in the demonstration of cardiac and extra-cardiac structures, especially in paediatric patients. The most important advantage is that it provides more and more accurate information quickly and reliably. Due to the high spatial resolution and large imaging area, the drainage location of the abnormal veins can be determined easily, along
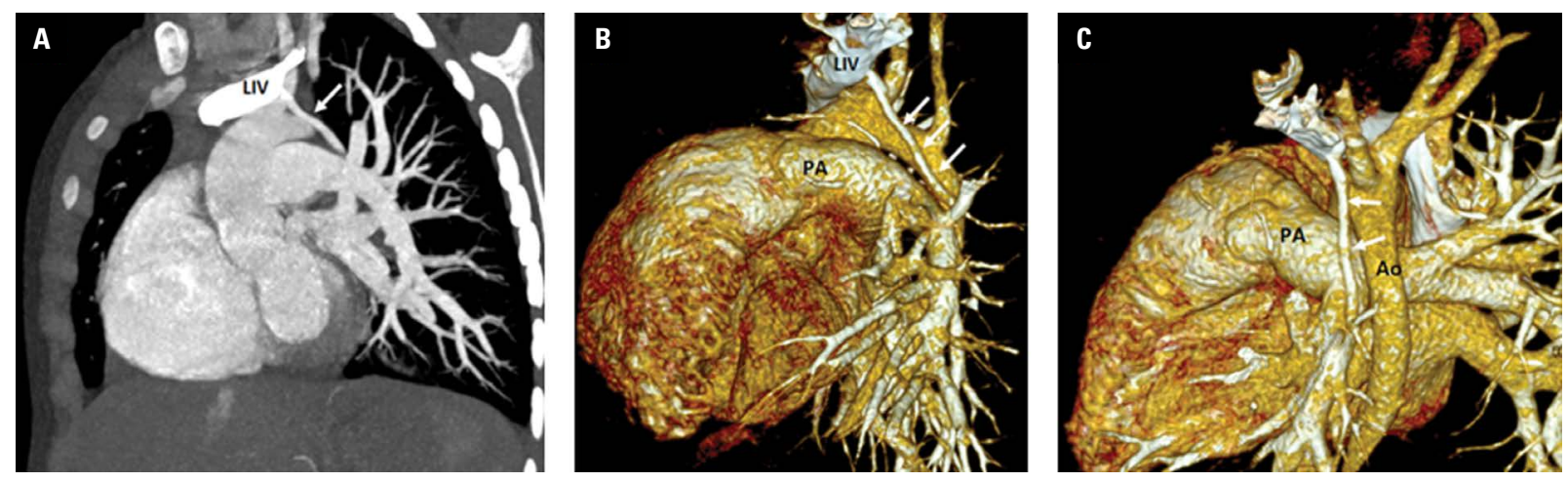

Figure 8. A-C. In a 10-year-old female patient an accessory left pulmonary vein drains into left innominate vein. Sagittal maximum intensity projections computed tomography image (A), lateral (B) and posterior three-dimensional volume rendered images demonstrate accessories pulmonary vein (white arrows) drains into left innominate vein (LIV); PA — pulmonary artery; $\mathrm{Ao}$ — aorta.

Table 1. Additional cardiac and pulmonary findings in patients with total and pulmonary venous return anomalies

\begin{tabular}{lcccccccc}
\hline & Patient number & ASD & PDA & PSVC & Aortic coarctation & Pulmonary infiltration & Atelectasis & Lobar emphysema \\
\hline TPVRA & 10 & 10 & 1 & - & - & 2 & 2 & 1 \\
PPVRA & 31 & 12 & 3 & 4 & 2 & 10 & 7 & 5 \\
\hline
\end{tabular}

ASD — atrial septal defect; PDA — patent ductus arteriosus; PPVRA — partial pulmonary venous return anomaly; PSVC — persistent superior vena cava; TPVRA — total pulmonary venous return anomaly 
with complex cardiac anomalies and lung disease. Furthermore, it is a non-invasive technique and does not require sedation like catheter angiography.

In a study published by Huang et al. [12], the effective radiation dose was $1.6+0.3 \mathrm{mSv}$ (range: 1.1-2.5 mSv) in infants with congenital heart disease. Bonelli-Sica et al. [2] reported that the overall effective radiation dose was $1.01 \mathrm{mSv}$ (range: $0.13-6.43 \mathrm{mSv}$ ) for older children and $0.78 \mathrm{mSv}$ (range: $0.13-4.16 \mathrm{mSv}$ ) for patients younger than 1 year old. In another study performed by Turkvatan et al. [20], the effective radiation dose was $1.12 \mathrm{mSv}$ (range: $0.15-4.17 \mathrm{mSv}$ ) for older children and $0.58 \mathrm{mSv}$ (range: $0.15-0.73 \mathrm{mSv}$ ) for patients younger than 1 year old among paediatric patients with PPVRA. In our study, the effective radiation dose was slightly less than in previous studies.

All pulmonary veins are drained to the right circulation in TPVRA, and the most common type is supracardiac. The presence of obstruction is very important in the diagnosis of patients with TPVRA. In this study, the rate of supracardiac TPVRA was most frequently correlated with previous studies [13]. However, the rates of the other types were found to be slightly higher since no cases of the infracardiac type were seen, which was probably because of the small number of patients. PPVRA occurs as a result of abnormal drainage of one or more pulmonary veins, but not all. An abnormal pulmonary vein can drain into any systemic vein from the SVC to the portal vein, and the most common on the right is the drainage into the SVC. The most common form on the left is one in which the left upper lobe drains into the innominate vein.

The lobar distribution of pulmonary anomalies in our study was the most frequent right anomalous vein draining into SVC, similar to other studies $[2,7]$. The findings were the same as $\mathrm{CT}$ findings in patients undergoing catheter angiography. This suggests that although catheter angiography is the gold standard, high-pitch CT angiography could assume the diagnostic role of this invasive procedure. PPVRA is usually asymptomatic in children. According to the degree of anomaly, symptoms may develop in the following years due to the left-to-right shunt.

Pulmonary venous return anomaly can be accompanied by many cardiac anomalies, and ASD is the most common. Although the presence of different anomalies has been shown, the most common was ASD, which was present in $39 \%$ of the cases in the present study, similar to the study by Turkvatan et al. [20]. In this study, we evaluated lung anomalies together with cardiac anomalies, in contrast to other studies. The detection of lung diseases was especially important for patients who would undergo surgery. In these patients, medical treatment was applied, and then surgery was performed.

\section{Limitations of the study}

There were some limitations in our study. Firstly, the technique involves radiation, albeit a reduced amount. Secondly, only CT scans were examined retrospectively in some patients. Therefore, false negatives in $\mathrm{CT}$ could not be determined. Third, the number of patients was low, although this is one of the largest studies to evaluate both TPVRA and PPVRA.

\section{CONCLUSIONS}

In conclusion, this study confirms that high-pitch low-dose CT is an easy, robust, and rapid diagnostic method for detecting abnormal venous return anomaly in paediatric patients. In addition, other types of cardiac and great vascular anomalies can be detected very quickly by the high-pitch low-dose CT. This important information may change treatment strategies for patients with suspected PVRA.

\section{REFERENCES}

1. Alsoufi B, Cai S, Van Arsdell GS, et al. Outcomes after surgical treatment of children with partial anomalous pulmonary venous connection. Ann Thorac Surg. 2007; 84(6): 2020-6; discussion 2020, doi: 10.1016/j. athoracsur.2007.05.046, indexed in Pubmed: 18036929.

2. Bonelli-Sica JM, de la Mora-Cervantes R, Diaz-Zamudio M, et al. Dual-source 256-MDCT for diagnosis of anomalous pulmonary venous drainage in pediatric population. Am J Roentgenol. 2013; 200(2): W163-W169, doi: 10.2214/ AJR.11.8348, indexed in Pubmed: 23345380.

3. Davia J, Cheitlin M, Bedynek J. Sinus venosus atrial septal defect: Analysis of fifty cases. Am Heart J. 1973; 85(2): 177-185, doi: 10.1016/0002-8703(73)90458-4.

4. Delisle G, Ando M, Calder AL, et al. Total anomalous pulmonary venous connection: Report of 93 autopsied cases with emphasis on diagnostic and surgical considerations. Am Heart J. 1976; 91(1): 99-122, doi: 10.1016/s00028703(76)80440-1, indexed in Pubmed: 1244724.

5. Dillman JR, Yarram SG, Hernandez RJ. Imaging of pulmonary venous developmental anomalies. Am J Roentgenol. 2009; 192(5): 1272-1285, doi: 10.2214/AJR.08.1526, indexed in Pubmed: 19380552.

6. Fourdrain A, De Dominicis F, Bensussan M, et al. Three-dimensional computed tomography angiography of the pulmonary veins and their anatomical variations: involvement in video-assisted thoracoscopic surgery-lobectomy for lung cancer. Folia Morphol. 2017; 76(3): 388-393, doi: 10.5603/FM.a2016.0081, indexed in Pubmed: 28026848. 
7. Gao Y, Lu B, Hou Z, et al. Low dose dual-source CT angiography in infants with complex congenital heart disease: a randomized study. Eur J Radiol. 2012; 81(7): e789-e795, doi: 10.1016/j.ejrad.2012.03.023, indexed in Pubmed: 22525595.

8. Gathman GE, Nadas AS. Total anomalous pulmonary venous connection: clinical and physiologic observations of 75 pediatric patients. Circulation. 1970; 42(1): 143-154, doi: 10.1161/01.cir.42.1.143, indexed in Pubmed: 5425587.

9. Han BK, Lindberg J, Grant K, et al. Accuracy and safety of high pitch computed tomography imaging in young children with complex congenital heart disease. Am J Cardiol. 2011; 107(10): 1541-1546, doi: 10.1016/j. amjcard.2011.01.065, indexed in Pubmed: 21539949.

10. Herlong JR, Jaggers JJ, Ungerleider RM. Congenital Heart Surgery Nomenclature and Database Project: pulmonary venous anomalies. Ann Thorac Surg. 2000; 69(4 Suppl): S56-S69, doi: 10.1016/s0003-4975(99)01237-0, indexed in Pubmed: 10798417.

11. Ho ML, Bhalla $S$, Bierhals $A$, et al. MDCT of partial anomalous pulmonary venous return (PAPVR) in adults. J Thorac Imaging. 2009; 24(2): 89-95, doi: 10.1097/ RTI.0b013e318194c942, indexed in Pubmed: 19465830.

12. Huang $\mathrm{Mp}$, Liang $\mathrm{Ch}$, Zhao $\mathrm{Zj}$, et al. Evaluation of image quality and radiation dose at prospective ECG-triggered axial 256-slice multi-detector $\mathrm{CT}$ in infants with congenital heart disease. Pediatr Radiol. 2011; 41(7): 858-866, doi: 10.1007/s00247-011-2079-2, indexed in Pubmed: 21534003.

13. Kim $\mathrm{TH}$, Kim YM, Suh $\mathrm{CH}$, et al. Helical $\mathrm{CT}$ angiography and three-dimensional reconstruction of total anomalous pulmonary venous connections in neonates and infants. Am J Roentgenol. 2000; 175(5): 1381-1386, doi: 10.2214/ ajr.175.5.1751381, indexed in Pubmed: 11044048.

14. Klink T, Müller G, Weil J, et al. Cardiovascular computed tomography angiography in newborns and infants with suspected congenital heart disease: retrospective evaluation of low-dose scan protocols. Clin Imaging. 2012; 36(6): 746-753, doi: 10.1016/j.clinimag.2012.01.043, indexed in Pubmed: 23154004.

15. Muñoz Castellanos L, Sánchez Vargas CA, Kuri Nivon M. [Morphopathologic study of total anomalous pulmonary venous connection]. Arch Cardiol Mex. 2007; 77(4): 265-274, indexed in Pubmed: 18361070.

16. Roehm JO, Jue KL, Amplatz K. Radiographic features of the scimitar syndrome. Radiology. 1966; 86(5): 856-859, doi: 10.1148/86.5.856, indexed in Pubmed: 5936095.

17. Seale AN, Uemura H, Webber SA, et al. British Congenital Cardiac Association. Total anomalous pulmonary venous connection: morphology and outcome from an international population-based study. Circulation. 2010; 122(25): 2718-2726, doi: 10.1161/CIRCULATIONAHA.110.940825, indexed in Pubmed: 21135364.

18. Shen $\mathrm{Q}, \mathrm{Pa} \mathrm{M}, \mathrm{Hu} X$, et al. Role of plain radiography and $\mathrm{CT}$ angiography in the evaluation of obstructed total anomalous pulmonary venous connection. Pediatr Radiol. 2013; 43(7): 827-835, doi: 10.1007/s00247-012-2609-6, indexed in Pubmed: 23341089.

19. Sreeram N, Walsh K. Diagnosis of total anomalous pulmonary venous drainage by Doppler color flow imaging. J Am Coll Cardiol. 1992; 19(7): 1577-1582, doi: 10.1016/07351097(92)90620-3.

20. Türkvatan A, Tola HT, Kutlutürk N, et al. Low-Dose computed tomographic imaging of partial anomalous pulmonary venous connection in children. World J Pediatr Congenit Heart Surg. 2017; 8(5): 590-596, doi: $10.1177 / 2150135117723903$, indexed in Pubmed: 28901235.

21. Vyas HV, Greenberg SB, Krishnamurthy R. MR imaging and $C T$ evaluation of congenital pulmonary vein abnormalities in neonates and infants. Radiographics. 2012; 32(1): 87-98, doi: 10.1148/rg.321105764, indexed in Pubmed: 22236895. 